
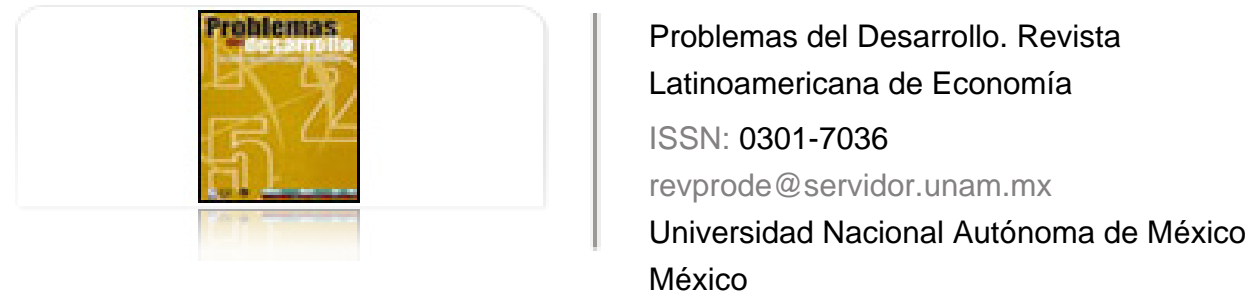

Méndez Rodríguez, Alejandro

¿Emigrar para volver?: de la asimilación al transnacionalismo

Problemas del Desarrollo. Revista Latinoamericana de Economía, vol. 38, núm. 148, enero-marzo, 2007, pp. 99-126

Universidad Nacional Autónoma de México

Distrito Federal, México

Disponible en: http://www.redalyc.org/articulo.oa?id=11820155005

- Cómo citar el artículo

- Número completo

- Más información del artículo

Página de la revista en redalyc.org

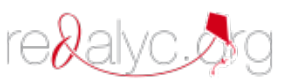

Sistema de Información Científica

Red de Revistas Científicas de América Latina, el Caribe, España y Portugal Proyecto académico sin fines de lucro, desarrollado bajo la iniciativa de acceso abierto 


\section{¿EMIGRAR PARA VOLVER?: \\ DE LA ASIMILACIÓN AL TRANSNACIONALISMO}

\section{Alejandro Méndez Rodríguez*}

Fecha de recepción: 6 de octubre de 2006. Fecha de aceptación: 16 de enero de 2007.

\section{Resumen}

La idea central del artículo gravita en torno de la evolución y cambio del proceso de asimilación de los inmigrantes en Estados Unidos y en el contexto conceptual y lo singular de los lazos transfronterizos que establecen los emigrantes con su país de origen, y que en cierto sentido le otorgan una acepción particular tanto al paradigma del transnacionalismo como a la categoría del migrante transnacional. El transnacionalismo se erige como la nueva transformación de los modelos de incorporación de los inmigrantes. En el caso de los emigrantes mexicanos, el espacio social transnacional está configurado por la política migratoria de Estados Unidos, por el carácter y volumen de la migración indocumentada y por las escasas acciones gubernamentales mexicanas.

Palabras clave: asimilación, transnacionalismo, inmigración indocumentada, migración transnacional, espacio social transnacional.

* Investigador titular de la Unidad Economía de la Educación, la Ciencia y la Tecnología del Instituto de Investigaciones Económicas de la Universidad Nacional Autónoma de México. El autor agradece el apoyo y facilidades otorgadas por Tom Langford, jefe del Departamento de Sociología de la Universidad de Calgary, Canadá, así como a Juan Arroyo por su colabo ración en el procesamiento de los datos.Correo electrónico: menrod@servidor.unam.mx 


\section{ALEJANDRO MÉNDEZ RODRÍGUEZ}

Abstract

The core idea of this paper revolves around movement and change in the process of assimilation of immigrants in the United States and in the conceptual and singular context of trans-border links that emigrants establish with their country of origin, which to some extent grant a particular acceptance within both the paradigm of transnationalism and the category of the transnational migrant. Transnationalism is established as the new transformation of models for the incorporation of immigrants. In the case of Mexican emigrants, the transnational social space is formed via U.S. migratory policy, by the nature and volume of undocumented migration and by the limited actions of the Mexican government.

Key words: assimilation, transnationalism, undocumented immigration, transnational migration, transnational social space.

\section{Résumé}

L'article traite de l'évolution et du changement de processus d'assimilation des immigrants aux États-Unis et est centré sur le contexte conceptuel et la singularité des liens transfrontaliers qu'établissent les émigrants avec leur pays d'origine, liens qui confèrent en quelque sorte une signification particulière tant au paradigme du transnationalisme qu'au statut de migrant transnational. Le transnationalisme s'érige comme la nouvelle transformation des modèles d'incorporation des immigrants. Dans le cas des émigrants mexicains, l'espace social transnational est configuré par la politique des États-Unis en matière d'immigration, par la nature et l'importance de l'immigration clandestine et par les rares actions du gouvernement mexicain.

Mots clés: assimilation, transnationalisme, immigration clandestine, migration transnationale, espace social transnational.

\section{Resumo}

A idéia central do artigo gravita em torno da evolução e modificação do processo de assimilação dos imigrantes nos Estados Unidos e sobre o contexto conceitual e a singularidade dos laços transfronteiriços que estabelecem os emigrantes com o seu país de origem, e que em certo sentido outorgam uma acepção particular tanto ao paradigma do transnacionalismo como à categoria do migrante transnacional. $O$ transnacionalismo se erege como a nova transformação dos modelos de incorporação dos imigrantes. No caso dos emigrantes mexicanos, o espaço social transnacional está configurado pela política migratória dos Estados Unidos, pelo caráter e volume da migração indocumentada e pelas escassas ações governamentais mexicanas.

Palavras chave: assimilações, transnacionalismo, imigração indocumentada, migração transnacional, espaço social transnacional. 
$\mathcal{L}$ a idea central de este trabajo gravita en torno del esquema conceptual de lo singular de los lazos transfronterizos que establecen los emigrantes mexicanos radicados, principalmente, en Estados Unidos con sus comunidades de origen, y que en cierto sentido le otorgan una acepción particular al paradigma del transnacionalismo. Esos lazos constituyen un espacio de flujos transnacionales que dan cuenta de los límites de los modelos clásicos de asimilación o integración presentes de manera abundante y sobresaliente en la literatura social estadounidense. La complejidad del proceso de la migración en el marco de la ampliación de los espacios transnacionales del capital, bienes y servicios plantea un nuevo debate de las características, modalidades, tipos y conceptos de la movilidad internacional de la población. Los viejos términos de inmigrante como formador de nuevos asentamientos, y del emigrante —otra imagen del caleidoscopio — como la persona que rompe con sus raíces, han sido motivo de un nuevo debate que conjuga los dos elementos antípodas de la migración (origen-destino; emisor-receptor, ida-regreso) y que se materializan en la perspectiva teórica del transnacionalismo y de manera particular en la categoría del migrante transnacional (transmigrante), es decir, el ente social que mantiene, utilizando una analogía, un pie en el país de origen y el otro en la sociedad receptora.

La emergencia de la nueva figura del transmigrante puede ubicarse en el rompimiento teórico con la visión social del proceso de adaptación; sin embargo, más que una expresión histórica de la fase de la globalización, los transmigrantes son los indicadores de lo que se puede llamar migración globalizada, que da origen a los flujos de migración y mantiene una racionalidad económica en ellos. La transmigración, desde ese punto de vista, es el desplazamiento físico de las personas fuera de las fronteras nacionales sin ausencia presencial. Con esta idea, la migración transnacional, como parte de la migración globalizada, está compuesta por todas aquellas prácticas de carácter tanto socioeconómico como político que tienen como fin establecer y recrear el vínculo entre el inmigrante y el lugar emisor. Con esta definición, la tesis básica es que el transnacionalismo y, en particular, la transmigración, pueden ser conceptuadas, en parte, como extensión de la asimilación de inmigrantes que crean una dimensión espacial de cruce de naciones. Así, los diversos discursos acerca de los modelos de asimilación han dado un giro hacia el transnacionalismo para 
explicar la amplitud del proceso de migración que incluye, de manera relevante, la migración transnacional, la de regreso y el retorno de migrantes.

El objetivo de este trabajo es ofrecer una reflexión sistemática de algunos elementos conceptuales de las teorías de la migración para enmarcar el estudio del fenómeno de la emigración mexicana.

\section{Los paradigmas de la asimilación: de la americanización ${ }^{1}$ a la transnacionalización}

Durante la primera mitad del siglo xx los enfoques teóricos de la migración se agruparon en dos modalidades: la primera abarca los estudios de alcance microanalítico, en los cuales se incluyen los análisis de comunidades respecto del cambio del ambiente sociocultural. En segundo lugar, los estudios macroteóricos, que examinan los aspectos históricos y estructurales, y que de manera general consideran a las migraciones como un proceso social de redistribución de la población dentro del contexto de la sociedad global (Herrera, 2006:25-27). En el último cuarto del siglo $\mathrm{xx}$, nuevos paradigmas, como el transnacionalismo, emergen para explicar las nuevas formas de integración de los migrantes.

De manera esquemática, en el centro de la formulación de la teoría de migración durante el siglo xx se encuentran los conceptos comunidad y etnicidad. El primero surge en los albores de ese siglo con los planteamientos de Tonnies (1963),

1 El americanismo tiene su antecedente en la política exterior de Tomas Jefferson, que a prin cipios del XIX, sostenía: "nunca mezclarnos en las riñas de Europa, nunca tolerar que Europa se inmiscuya en asuntos de este lado del Atlántico". Esta política se cristaliza en la doctrina de James Monroe, de 1823, que formaliza la práctica de "América para los ame ricanos". Dicha doctrina estableció la base de la hegemonía de Estados Unidos en el continente americano. Otro hecho significativo del americanismo se registra en 1904, cuando el presidente de Estados Unidos, Theodore Roosevelt, establece el derecho de intervenir en otras naciones cuando los intereses estadounidenses estuvieran amenazados. Durante el siglo xx, la intervención de Estados Unidos en los países latinoamericanos fue notable, por ejemplo en 1965, con la doctrina Johnson, varios cientos de infantes de la marina desembarcaron en la República Dominicana con el fin de evitar el triunfo del pueblo sobre la dictadura militar. El americanismo se ha expresado desde el siglo xIX como una amenaza real a la soberanía de las naciones, ya que limita y cancela los principios de la autodeterminación y de no intervención entre países. En este contexto, el término americanización tiene su apogeo a finales del siglo xIx y se constituye en una ideología que expresa un estilo de vida y la categoría jurídico política del ciudadano. El icono de la americanización tiene su opuesto en la inmigración. La primera reconoce los derechos políticos y sociales de una parte de la población; y, en cambio, la segunda considera exclusivamente los derechos básicos de los individuos como fuerza de trabajo. 
y posteriormente adquiere diversas dimensiones. De manera general, se concibe la comunidad como: $a$ ) un lugar; $b$ ) personas que comparten intereses comunes y ambiente comunitario; c) como una red de personas que no necesariamente están juntas; $d$ ) como una red; y $e$ ) como un espacio.

En el caso de la etnicidad, cabe señalar que ésta se expresa en la delimitación del grupo étnico, el cual implica principalmente el sentimiento de pertenencia. Dicho grupo se compone de diferentes aspectos, por ejemplo: nacionalidad, raza, ${ }^{2}$ culto y país de origen. La combinación de esos elementos revela y configura un tipo específico de grupo. El concepto grupo étnico se observa en prácticas religiosas, valores, música, literatura, lenguaje, comida, recreación de tradiciones y sensación de un pasado común. También se manifiesta en el vestido, los modales, la expresión emocional y, por supuesto, en el acento al hablar. En 1919, en Estados Unidos se hablaban cerca de 44 lenguas entre las comunidades de inmigrantes (Park, 1922:3).

Al clasificar a la población de inmigrantes a partir del criterio de etnicidad, se abrieron las puertas a extensos estudios de microanálisis de diversas comunidades que en los años sesenta se consolidaron en áreas de investigación en ciencias sociales y destacaron en las siguientes disciplinas: sociología, historia y literatura, por ejemplo, los estudios de la población asiático-americana (Grewal, 2005), los latinoamericanos, los mexicano-americanos, entre otros. En ellos se desarrolla la idea de explicar las formas y mecanismos de incorporación de esos inmigrantes a la sociedad receptora mediante la asimilación, acomodamiento, aculturación y unión, esta última como resultado de matrimonios interraciales.

Las teorías del proceso de migración durante el siglo xx han girado en torno del modo en el cual los inmigrantes recientes cambian su comportamiento una vez que arriban al país destino. El punto de vista convencional considera que los inmigrantes modifican sus pautas de comportamiento social y económico para adaptarse a la cultura dominante de la sociedad receptora. En el caso de la inmigración en Estados Unidos, abundan estudios acerca de diversos grupos étnicos. Así, se han realizado

2 El concepto de raza empleado en el pensamiento social a principios del siglo xx estuvo marcado por el principio del determinismo biológico. El elemento central de su definición recaía de manera limitada en los caracteres visibles del individuo, como por ejemplo, el color de la piel. El concepto raza se ha transformado a raíz de la segunda guerra mundial, la des colonización de África y los movimientos sociales que han enarbolado los derechos humanos. Las nuevas categorías que emergen son etnicidad, nacionalidad y minorías. A partir de los años sesenta, el término raza es superado y adquiere mayor relevancia el vocablo referente a lo étnico como una forma de agrupar a la población. 
investigaciones que capturan el significado de la vida económica y social de las comunidades étnicas de inmigrantes. En dichos estudios sobre inmigrantes, en el caso de Estados Unidos, surgen términos como americanización, mainstream (tendencia principal), core-group (grupo nuclear, como las viejas familias yanquis), core-society (sociedad nuclear o central, como la anglosajona), core-culture (cultura central como los blancos y protestantes) para denominar a la sociedad host (receptora o huésped).

Desde sus orígenes, la teoría de la migración ha descansado en el concepto asimilación. A principios del siglo xx se hace notar que este término está vinculado con el proceso metabólico de los organismos vivos e implica la concepción de que en la sociedad humana es similar al de un organismo, en el cual la asimilación es parte del proceso de nutrición (Fairchild, 1926:137). De manera tradicional, los estudios sobre migración se han centrado en explicar las respuestas de los inmigrantes frente al nuevo entorno económico y social, y en ocasiones suscitan conflictos entre las comunidades de inmigrantes que se expresa claramente en la segregación residencial y ocupacional. Desde principios del siglo xx se alertaba de la dificultad de la asimilación de inmigrantes; por ejemplo, el caso de John Smith, relatado por Henry Pratt Fairchild (1926:172-173), pregunta por qué debe esperarse la asimilación de los extranjeros en Estados Unidos, cuando no concebimos que los estadounidenses sean asimilados en tierras extranjeras.

El principal icono de la investigación sobre la asimilación es la Escuela de Chicago, desde el punto de vista de la ecología humana de los años veinte (Theodorson, 1974), que cuenta con estudios exhaustivos sobre comunidades étnicas, por ejemplo, la vida de los polacos, que a partir del análisis de la correspondencia se reconstruye la experiencia de migrar de ese grupo. Cabe destacar que su uso es clave en los estudios sobre migración en las primeras décadas del siglo xx; por ejemplo, en esos mismos años (1924-1930), las cartas de los inmigrantes alemanes en Canadá (Ganzevoort, 1999) dan cuenta de las razones de la emigración, sus deseos, miedos y su experiencia de vivir en ese país.

De manera general, en las primeras décadas del siglo pasado, la teoría de la migración se basó en el análisis de los flujos de europeos hacia América, de tal forma que la preocupación intelectual recayó en el problema del aislamiento y alienación de esos inmigrantes. No obstante la presencia de diversas instituciones sociales que reforzaban y reproducían la identidad de los inmigrantes, éstos eran descritos como "desarraigados". También los inmigrantes europeos eran etiquetados como "aislados", a pesar de que la Iglesia y la prensa étnica desempeñaban un papel clave en la 
integración, ya que en ellas el inmigrante conservaba lazos con su origen, y también se mantenía la lucha política y la oportunidad de formar parte de la sociedad receptora (Park, 1922:50-51).

Así, la idea de la americanización de los múltiples grupos étnicos cobra importancia como el principal prototipo de la formación de la nacionalidad. La americanización ha sido el eje de las formulaciones conceptuales de la incorporación de los inmigrantes. Las ideologías han pasado de la americanización plena (Gordon, 1964), que ofrece el ejemplo ficticio de la asimilación completa entre los grupos de los sylvanias y los mundovians, hasta las mezclas, como los afroamericanos, los chinoamericanos, los americano-japoneses, entre otros.

La expresión más utilizada ha sido asimilación y ha estado acompañada de aculturación. En ocasiones, son utilizados indistintamente, aunque el primero es de corte sociológico y el segundo antropológico. El término aculturación data de los años treinta del siglo pasado, y fue formulado por el Subcomité de Aculturación del Social Science Research Council (Gordon, 1964:61). La aculturación es el resultado del encuentro continuo de los grupos sociales y subraya el comportamiento cultural. El concepto asimilación fue acuñado por Robert E. Park y Ernest W. Burgess, quienes lo definen como "un proceso de interpenetración y fusión, en el cual las personas o grupos adquieren los recuerdos, los sentimientos y las actitudes de otras personas o grupos y, participando de su historia y de su experiencia se fusionan en una vida cultural común" (Park y Burgess, 1921:735).

Después de la aportación conceptual de la Escuela de Chicago, los planteamientos de Gordon (1964:31-32) impulsaron el modelo de la asimilación a partir de la aplicación de la teoría del grupo primario y secundario al estudio de los inmigrantes, así como de los términos subsociedad y la subcultura. El grupo étnico en particular desarrolla una red de organizaciones y relaciones sociales informales que facilita el establecimiento de relaciones primarias y secundarias (Gordon, 1964:34). Uno de los trabajos clásicos sobre la asimilación de esa época parte del análisis de las clases sociales, que son la expresión jerárquica de tres dimensiones: el poder económico, político y el estatus social (Gordon, 1958). Gordon aborda el tema de la historia de la inmigración norteamericana, atendiendo los problemas de los prejuicios y la discriminación entre las razas, religiones y nacionalidad que surgen en las relaciones entre los grupos, en donde no se cumple el principio de la igualdad de oportunidades. Cabe señalar que esos planteamientos no sólo se derivan de la sociedad estadounidense, sino que reflejan la situación de las relaciones intergrupales de cualquier sociedad urbanizada e industrializada con población heterogénea. 
Cuadro 1

Variables de la asimilación completa

\begin{tabular}{lll}
\hline \multicolumn{1}{c}{ Subproceso } & Tipos de asimilación & Término \\
\hline $\begin{array}{l}\text { Cambio de los patrones culturales asociados } \\
\text { por los propios de la sociedad receptora }\end{array}$ & $\begin{array}{l}\text { Cultural } \\
\text { De comportamiento }\end{array}$ & Aculturación \\
$\begin{array}{l}\text { Penetración en gran escala en los círculos, } \\
\text { clubes e instituciones de dicha sociedad } \\
\text { en el nivel del grupo primario }\end{array}$ & Estructural & Ninguno \\
$\begin{array}{l}\text { Matrimonios mixtos en gran escala } \\
\begin{array}{l}\text { Sentimiento de constituir un solo pueblo, basado } \\
\text { exclusivamente en la sociedad receptora }\end{array}\end{array}$ & De identificación & Ninguno \\
$\begin{array}{l}\text { Ausencia de prejuicios } \\
\text { Ausencia de discriminación }\end{array}$ & $\begin{array}{c}\text { De actitud abierta } \\
\text { De comportamiento }\end{array}$ & Ninguno \\
\hline $\begin{array}{l}\text { Ausencia de conflictos de valor y poderes } \\
\text { abierto }\end{array}$ & Cívica & Ninguno \\
\hline
\end{tabular}

La asimilación estructural era la pieza clave para la extinción de los grupos étnicos y su integración al patrón de comportamiento de la cultura estadonidense dominante. Esta asimilación estaba compuesta por diversos subprocesos (Gordon, 1964:71).

Como se ha mencionado de manera breve, los procesos de integración, asimilación o adaptación de los inmigrantes en la sociedad receptora han dado lugar a diversas teorías, como la ecología humana y la de los grupos sociales. Ahora bien, esos procesos se han expresado en diversos modelos de asimilación durante el siglo $\mathrm{xx}$, algunos de ellos son el melting pot (crisol) de principios de siglo xx y el transnacionalismo de finales de siglo.

\section{Melting pot}

El melting pot se basa en la idea de americanización, que parte del supuesto de la superioridad de la cultura, e indicaba que la adaptación plena a la sociedad (core $o$ núcleo) demandaba la renuncia completa a la cultura ancestral de los inmigrantes en favor de los valores y comportamiento de la cultura anglosajona. El melting pot ha sido un símbolo mediante el cual se transforma al inmigrante en ciudadano. La primera noticia formal que se tiene de este icono se encuentra en la obra de teatro de Israel Zangwill, escrita a principios del siglo xx, intitulada The Melting-Pot. En ésta 
se plantea la fusión de diversas nacionalidades en Estados Unidos y la pérdida de las identidades originales (Zangwill, 1908). Esa inquietud se muestra en los anexos de la obra de teatro, en los cuales se indica que 1.5 millones de personas habían llegado a América provenientes de 42 países (Nahshon, 2006:366), lo cual provocaba la formación de colonias de extranjeros, como la Pequeña Italia, la Pequeña Hungría, entre otras. Naturalmente, ante la representación de la obra de teatro se expresaron críticas que la calificaron como una mezcla de insípidas frases sin reflexión histórica. Se decía, por ejemplo, que la comunidad alemano-americana no había sido formada por expulsados como grupo en busca de ayuda o protección, sino que habían migrado para formar parte de la nación estadounidense (Park, 1922:61).

El melting pot fue constituido símbolo de la unificación en el marco de la ideología del orden, progreso y estabilidad. Dicha unificación se basó en el factor raza y en la nacionalidad, lealtad y patriotismo (Fairchild, 1926). A principios del siglo pasado, los Comités de Americanización tenían como objetivo que todos los habitantes fueran nacionalizados, y se anunciaban en los siguientes términos: "Tú vives en América, Tú trabajas en América, ¿por qué no ser parte de América? La ciudadanía te hace parte de América".

El melting pot es considerado un proceso que conduce a la formación del ciudadano, que entonces no era sólo un programa educativo, sino espiritual y de transformación emocional (Fairchild, 1926:168). La americanización es considerada la fusión de los pueblos norteamericanos con los inmigrantes en las relaciones y actividades fundamentales de la vida nacional. En el marco del estudio de las comunidades de inmigrantes y las instituciones culturales, la prensa escrita de inmigrantes constituye un método de americanización, ya que ella da cuenta de la vida de éstos que se encaminan hacia un nuevo ambiente cultural (Park, 1922). Las noticias de la prensa extranjera ofrecen información que el individuo usa para ajustarse al medio ambiente y cambiar sus hábitos.

El concepto melting pot supone el intercambio de valores para formar un nuevo sistema cultural. Es decir, los inmigrantes son aceptados y cambian (¿qué cambian o cómo?), es una especie de mezcla biológica de la población anglosajona con los grupos inmigrantes. El nuevo grupo no reconoce la existencia de las minorías. Así, se suponía que Estados Unidos se había convertido en un melting pot, en el cual los diferentes grupos y nacionalidades habían dejado sus discursos y sus costumbres para convertirse en estadounidenses. El melting pot suponía que el lenguaje y la cultura cambiarían conforme pasaran las generaciones, ya que las 
personas de todos los grupos y credos tenían igualdad de oportunidades. Cuando la superioridad del autóctono, oriundo, nacional, es aceptada y emulada, a esta aculturación se le conoce como americanización. Se decía que América puede ser un melting pot y la americanización el camino de la asimilación (Kallen, 1956:96).

Naturalmente, en la idea del melting pot subyace una visión romántica de las interrelaciones étnicas. En 1963 fue publicada la obra Beyond The Melting Pot de Nathan Glazer y Daniel P. Moynihan, la cual supera la concepción de las teorías sobre la inferioridad de los grupos. Otra crítica a este modelo de mezcla cultural planteaba que, más que un melting pot, se registra una transmutación, en la cual los ingredientes son transformados en la idealización del modelo anglosajón. Por tal razón, el gran obstáculo de la integración era la discriminación, el racismo y la falta de tolerancia expresadas en las políticas discriminatorias antimigrantes y en la presencia de la desigualdad en las minorías étnicas. Algunos casos dramáticos de racismo y discriminación se observan en las políticas de exclusión, por ejemplo, el fenómeno llamado el peligro amarillo, que simboliza el racismo blanco en respuesta a la inmigración oriental. A guisa de ejemplo, en el artículo XIX de la Constitución de California, el cual permaneció vigente de 1879 a 1952, prohibía a las corporaciones contratar trabajadores de origen chino (Steinfield, 1970).

En otros estudios se observa la presencia del mercado laboral dual que toma en cuenta los recursos de la etnicidad y se expresa en desigualdades laborales. Dicho mercado encierra conflictos debido al desplazamiento de la fuerza de trabajo cara por la barata, con lo cual emerge un antagonismo racial y étnico que se manifiesta en movimientos de exclusión y en el sistema de castas (Bonacich, 1972).

La americanización buscaba una cultura monolítica, la cual fue cambiada lentamente por una sustentada o apoyada en un pluralismo cultural. Los primeros atisbos sobre la reflexión del pluralismo cultural están descritos en "Democracy vs. The Melting Pot", publicado en The Nation, entre el 18 y 25 de febrero de 1915. En éste se indica que la civilización estadounidense ${ }^{3}$ podía representar la cooperación armónica de la civilización europea (Kallen, 1924:124-125). Brevemente, el pluralismo cultural postula la preservación de la vida comunal con sus expresiones culturales del grupo de inmigrantes dentro del contexto de ciudadanía estadounidense

3 En el contexto de la expansión del capitalismo a principios del siglo xx, la idea de la americanización y su vínculo con la formación de la ciudadanía fortalecieron una ideología que permitió que surgiera la expresión optimista de la formación de una civilización, con lo cual se ocultaban los mecanismos de conflicto, dominación y desigualdad en la sociedad. 
y la integración a su sociedad en el contexto democrático. En ese paradigma, el desarrollo de las comunidades étnicas es importante, pues tienen el derecho de mantener su cultura que, a su vez, enriquece la vida en ese país.

Si bien el concepto melting pot está asociado con la nacionalidad estadounidense, también ha formado parte de debates en sociedades multiétnicas que se enfrentan al fenómeno de la inmigración y la diversidad étnica mediante las ideas del multiculturalismo, universalismo y múltiples identidades.

\section{El transnacionalismo}

En países como Canadá, el transnacionalismo ha sido conceptuado como extensión del multiculturalismo con una orientación que va más allá de las fronteras, donde se crea una dimensión espacial de cruce de líneas fronterizas. Así, el transnacionalismo puede ser visto como una forma de adaptación del inmigrante (Satzewich 2006:4). Sin embargo, en algunas investigaciones sobre migración en Estados Unidos se representa el transnacionalismo como una ruptura con el concepto de la asimilación, ya que ese nuevo paradigma destaca las relaciones transfronterizas de los inmigrantes en el marco de la globalización que se expresa, por un lado, en el flujo de capitales de carácter corporativo transnacional, llamado "desde arriba", lo cual implica patrones de inversiones, reestructuración industrial y dominación de los medios de comunicación. Por otro, han surgido los movimientos "desde abajo", es decir, las transformaciones sociales e institucionales también son resultado de movimientos y redes transnacionales, tales como la organización laboral transfronteriza y la migración transnacional (Guarnizo, 1998:46).

Los principios básicos teóricos del transnacionalismo están presentes de manera explícita en el libro colectivo de Linda Basch (1995), en el cual a partir del estudio de los inmigrantes haitianos reconstruye el proyecto transnacional y la formación de un Estado sin territorio. Las premisas teóricas del transnacionalismo son: a) la migración transnacional está vinculada a las condiciones de capitalismo global y deben ser analizadas dentro del contexto de las relaciones globales entre el capital y el trabajo; $b$ ) el transnacionalismo es un proceso mediante el cual los migrantes crean campos sociales de cruces fronterizos por sus actividades diarias y relaciones sociales, políticas y económicas (Basch, 1995:22).

En términos esquemáticos, el transnacionalismo es el paradigma que reconoce el campo o espacio que se crea entre el lugar de origen y el de recepción de los migrantes. Ese paradigma emerge en el contexto de la reestructuración económica 
global y el reposicionamiento del Estado. El primero imprime mayor fuerza y amplitud a movimientos de trabajadores de todos los niveles de calificación. El segundo, se caracteriza por la desterritorialización del Estado-nación. Esos hechos están marcados por el flujo transnacional de capital y el desplazamiento transnacional de las personas, quienes son los agentes de ese tipo de migración, y que crea comunidades que se manifiestan en el campo o espacio social transnacional.

El transnacionalismo es un paradigma que atiende a un proceso binacional o multinacional de las relaciones políticas (Guarnizo, 1998), culturales (Appadurai, 2001) e interrelaciones económicas que en el ámbito de la migración se manifiestan en el llamado campo social transnacional, donde se establecen las conexiones y nexos entre la sociedad de origen y la sociedad receptora. Así, la migración transnacional toma lugar en los grupos de personas cuya economía, cultura y vida social se realiza por medio de las fronteras nacionales (Guarnizo, 1998:47). La migración transnacional constituye una fuerza significativa en la transformación de las instituciones de los países involucrados, por ejemplo, en los estudios migratorios contemporáneos se observa que las redes sociales de los inmigrantes trazan lazos transfronterizos para decidir hacia dónde migrar, cómo conseguir vivienda y cómo encontrar trabajo, con lo cual surgen los nichos laborales y económicos, entre otros. Así, los estudios transnacionales ilustran multitud de procesos sociales, económicos, culturales y demográficos que surgen al interior de las sociedades (Mahler, 1998).

Desde finales de los años noventa, el concepto de transnacionalismo ha sido considerado resbaladizo, ya que ha sido utilizado en distintos contextos. Sin embargo, en términos generales, el campo de éste se refiere a la red cultural, social, económica y de relaciones políticas construidas por los migrantes mediante las fronteras nacionales (Guarnizo, 1998:49). Además, es posible considerar al transnacionalismo como una nueva forma de integración de los inmigrantes, en particular los de origen latinoamericano, asiático y africano.

Una de las principales líneas de investigación en el transnacionalismo es la vinculación política de los inmigrantes con su país de origen. La organización de los inmigrantes transnacionales encaminada al activismo político se manifiesta en el establecimiento de vínculos entre los migrantes, los gobiernos de su lugar de origen y las políticas internacionales, lo cual conforma nuevos espacios sociales transnacionales que unen a los transmigrantes con los asuntos internos del país de origen. Esas relaciones transnacionales dan lugar a la redefinición de la identidad, la ciudadanía y el papel del Estado. Según Guarnizo, los estados tienden a construir una identidad 
nacional transterritorializada (Guarnizo, 1998:48). A manera de ejemplo, se concibe que la ciudadanía es un concepto que abarca una identidad nacional y cultural, sin embargo, con la presencia de la migración transnacional, ese concepto cambia principalmente en las sociedades de origen. Algunos países, como República Dominicana, Colombia y Ecuador, han optado por el derecho de la doble ciudadanía. Por su parte, en las naciones receptoras han surgido movimientos de carácter xenofóbico para garantizar la identidad ciudadana.

En el espacio social transnacional confluyen una multitud de fenómenos, tales como el inmigrante empresario transnacional, el flujo de remesas, la participación electoral de los migrantes, la constitución de nuevas instituciones transnacionales y, por supuesto, los movimientos sociales transnacionales. De tal suerte que el transnacionalismo se erige como una forma de integración en los países receptores y un mecanismo de reinserción en los países de origen.

\section{Migración, asimilación y transnacionalismo}

$\mathrm{Al}$ interior de las sociedades receptoras de inmigrantes, la política migratoria constituye un indicador de los alcances y límites de la asimilación y de la categoría del inmigrante ilegal, clandestino o indocumentado. En el caso de Estados Unidos, a principios del siglo xx, el eje de la política migratoria giraba en torno de la forma de seleccionar a los inmigrantes. Un siglo después, el centro de la discusión es cómo detener la migración ilegal (Martin, 2004). Ahora bien, ¿cuáles han sido las principales líneas de la política migratoria en Estados Unidos?

En primer lugar, The Alien Act, del 25 de junio de 1798, estableció la deportación de extranjeros considerados peligrosos para Estados Unidos. La ley del 3 de marzo de 1875 señalaba que los criminales, prostitutas, lunáticos, epilépticos y polígamos no podían entrar a ese país; The Immigration Act, del 5 de febrero de 1917, añadió a los extranjeros analfabetas. La ley del 14 de mayo de 1937, etiquetada como Gigoló Act, consideraba como deportables a quienes se casasen con el fin de permanecer en Estados Unidos. Como puede apreciarse, el sistema de la política migratoria de esa nación se remonta al siglo XVIII, siendo el siglo Xx el momento del desarrollo de la política migratoria, a partir de 1907, cuando el Congreso estadounidense creó la Comisión de Inmigración para realizar una investigación sobre el sistema de inmigración, cuyos resultados dieron lugar a la Immigration Act del 5 de febrero de 1917. Posteriormente, la legislación Johnson-Reed Act de 1924 estableció cuotas de inmigrantes por país. El 24 de diciembre de 1952, se formuló 
la Immigration and Nationality Act. Esta última elimina la raza como una barrera a la inmigración, así como la discriminación por género, y establece las cuotas de trabajadores calificados que se requerían en Estados Unidos, además, se añadían a la lista de exclusión y expulsión a comunistas y políticos radicales.

En septiembre de 2001, Estados Unidos introdujo nuevas cuotas de inmigración para el Sur de Asia, Medio Oriente y África. El número de visas H-IB descendió de 195 mil, en 2001, a 65 mil, en 2003. La oficina de Immigration and Naturalization Service (INs) se transformó en el Departamento de Homeland Security (Grewal, 2005).

En general, las políticas de inmigración han sido: $a$ ) sin restricción; $b$ ) con restricción cualitativa, por ejemplo, limitaciones a los extranjeros analfabetas, prostitutas, alcohólicos; c) con restricción cuantitativa, por ejemplo, en 1921 se estableció la cuota de 350 mil europeos; $d$ ) medidas de prohibición; en el siglo XIX no tenían permiso de entrada las personas de origen chino o japonés; y e) las medidas sobre la inmigración ilegal. Esta última es de particular interés en este trabajo por el volumen de inmigrantes mexicanos y latinoamericanos y su relación con el transnacionalismo.

La inmigración ilegal o indocumentada es comúnmente definida como la estancia de una persona que vive en un país sin contar con un permiso de residencia. Un tipo se deriva de la permanencia extemporánea de extranjeros con visa de turista o de estudiante. A ellos se les clasifica como overstayers o visa-abusers, y por el otro, las personas que ingresan y permanecen sin visa, es decir, los enter without inspection (EWIs). En cualesquiera de los casos, se estima que, por lo general, cuenta con apoyo de una red de parientes o amigos; está integrada por trabajadores que intentan permanecer temporalmente en el país receptor (settlers), los trabajadores que intentan regresar al país de origen después de una estancia prolongada (sojourners), los trabajadores que cruzan la frontera diariamente para trabajar (commuters).

El carácter ilegal del inmigrante abarca tanto al empleador de ellos como al inmigrante o indocumentado; por eso, la política migratoria considera dos herramientas para controlar el flujo de inmigrantes ilegales, que en términos periodísticos e ideológicos se denomina combate a la inmigración ilegal: $a$ ) la Patrulla Fronteriza (Border Patrol), a cargo de la detención de inmigrantes en la zona fronteriza; b) las políticas internas, que implican detener a los trabajadores extranjeros en los lugares de trabajo y establecer sanciones a los empleadores. De manera particular, el fenómeno de la inmigración ilegal está presente en la ley Simpson-Rodino, conocida como la Immigration Reform and Control Act (IRCA), emitida en 1986, la cual se compone de tres elementos: $a$ ) sanciones a los empleadores que contraten a 
inmigrantes que no cuenten con la autorización para trabajar; $b$ ) un programa de amnistía para inmigrantes ilegales con mayor tiempo de residencia; y $c$ ) incremento de recursos para la Patrulla Fronteriza.

Diversos intereses confluyen en la definición de políticas de control del proceso de migración ilegal: $a$ ) aquellos actores sociales que recomiendan medidas rígidas en contra de los inmigrantes; $b$ ) los empresarios que se benefician de los trabajadores ilegales manteniendo a los inmigrantes como trabajadores sin derechos políticos, por ejemplo, los propietarios de la tierra agrícola, las pequeñas, medianas y grandes empresas; y c) los actores que reconocen derechos políticos y sociales de los inmigrantes, como las organizaciones de mexicano-estadounidenses.

El Departamento de Estado de Estados Unidos ${ }^{4}$ planteó como grandes lineamientos para el proceso de inmigración mexicana (8 de abril de 1981) reducir la migración ilegal, facilitar el manejo de viajes legales, incluyendo la migración temporal de trabajadores, y mantener la estabilidad política mediante una válvula de seguridad (safety valve) para que México exporte desempleados. Se decía que cualquier medida draconiana para detener el empleo de trabajadores mexicanos podía afecta los intereses estadounidenses y sería desastroso para la economía mexicana y su estabilidad política.

Recientemente la propuesta HR4437 del legislador republicano James Sensenbrenner plantea el tratamiento de los inmigrantes ilegales como criminales, así como el derecho de sancionar a aquellos que ayuden a los inmigrantes ilegales, ello con el fin de combatir la inmigración ilegal, fortalecer el control fronterizo y reestablecer el funcionamiento de las leyes de inmigración. A partir de marzo de 2006, se han realizado marchas multitudinarias en protesta contra dicha propuesta. Las nuevas iniciativas de leyes de control de flujos de inmigrantes es la principal razón de la movilización, aunada la inequidad y, en algunos casos, a la desilusión social.

\section{Inmigración mexicana}

El movimiento de población mexicana fue notable en los albores del siglo xx en el ámbito interno, con lo cual se transformó de una sociedad rural a una urbana. Así, el desplazamiento de la población rural hacia las ciudades fue la característica principal del proceso de migración interna. Aunado a ello, se hizo evidente el desplazamiento de

4 Department of State, Background paper on U.S. policy regarding the legal and illegal flow of Mexican nationals into the U.S. Memo, issue date: April 8, 1981. Declassified date: Dec 7, 1997, reproducido en Declassifield Documents Reference System, Farmington Hills, Mich.: Gale Group, 2006. 
población que rebasa la frontera norte del país. Así, el desplazamiento de la población hacia Estados Unidos ha sido el rasgo fundamental de la migración internacional, tanto en forma temporal como en el Programa Bracero de 1942-1964 (Temporary migrant farm labor), así como los flujos de inmigrantes ilegales o indocumentados.

La Oficina de Censos estadounidense estima en 39.9 millones la población hispana (8.5 millones de familias), la cual representaba $13.7 \%$ de la población en 2003 . El pronóstico revela la cifra de 102.6 millones de hispanos, que equivaldrá a $24 \%$ de la población en 2050. En promedio, de la población hispana, 67\% proviene de México. Se calcula que anualmente emigran cerca de 400 mil mexicanos hacia Estados Unidos. Ese flujo migratorio está fuertemente marcado por la inmigración ilegal o indocumentada hispana que, según las cifras, registraba a 12 millones en 2006.

La inmigración ilegal está relacionada con la inmigración total. Los inmigrantes ilegales cuentan con un perfil de baja calificación laboral, por lo cual han sido considerados fuerza de trabajo barata. Por otro lado, la dimensión del fenómeno de la inmigración ilegal está cubierta por un manto oscuro que parte de que la mayoría de las estadísticas de deportación (Weintraub, 1980:8) depende claramente de las características económicas del periodo, por ejemplo, durante la depresión económica de 1930 a 1933 y en la operación Wetback de 1953 a 1954 se registra la deportación de gran cantidad de inmigrantes.

En el periodo 1920-1925, Gamio calculaba alrededor de 228 mil ilegales. Las razones de la ilegalidad se debían a las barreras impuestas por la ley de migración, por ejemplo, se estipulaba como requisito saber leer y escribir (Gamio, 1969:9-10). En realidad, no se cuenta con información precisa acerca de las dimensiones del fenómeno de la migración ilegal, no obstante, por lo general, el acelerado movimiento de la población mexicana hacia Estados Unidos ha sido documentado ampliamente por la prensa de ese país. En 1951, el periódico The New York Times ${ }^{5}$ publicó que casi un millón de inmigrantes mexicanos (wetbacks) atravesaban anualmente, a nado, de manera ilegal el río Grande. En 1975, se asentaba que los inmigrantes ilegales alcanzaban la cifra de 8.2 millones, de ellos 5.2 eran mexicanos. En 1977, el INS estimaba el ingreso anual de un millón de inmigrantes ilegales, a partir del número de detenciones realizadas tipo EWIs. En 1979, el Departamento de Estado señaló que la inmigración ilegal había aumentado desde 1960. Se estimaba en

5 Gladwin Hill, Million a year flee Mexico only to find peonage here, The historical New York Times, electronic resource, 25 de marzo de 1951. 
Cuadro 2

Población estimada de residentes no autorizados según países de origen, enero 1990 y 2000 (miles)

\begin{tabular}{lrr}
\hline País de origen & Población 2000 & 1990 \\
\hline Todos los países & 7000 & 3500 \\
México & 4808 & 2040 \\
El Salvador & 189 & 298 \\
Guatemala & 144 & 118 \\
Colombia & 141 & 51 \\
Honduras & 138 & 42 \\
China & 115 & 70 \\
Ecuador & 108 & 37 \\
República Dominicana & 91 & 46 \\
Filipinas & 85 & 70 \\
Brasil & 77 & 20 \\
Haití & 76 & 67 \\
India & 70 & 28 \\
Perú & 61 & 27 \\
Corea & 55 & 24 \\
Canadá & 47 & 25 \\
Otros & 795 & 537 \\
\hline
\end{tabular}

Fuente: us Department of Homeland Security (2003).

12 millones de ilegales, de los cuales $60 \%$ correspondía a mexicanos. ${ }^{6}$ En estos días, un documento del gobierno mexicano intitulado "México frente al fenómeno migratorio y hacia una política migratoria integral en la frontera sur" indica que en 2005 un millón 200 mil mexicanos intentaron internarse en Estados Unidos.

El Department of Homeland Security, que asume todas las funciones sobre la seguridad y que fue creado en 2002, informa que en 2000, los inmigrantes ilegales ascendían a 7 millones y representaban $2.5 \%$ de la población de Estados Unidos. En el debate actual, se insiste en la cifra de 12 millones. Sesenta y ocho por ciento de los inmigrantes ilegales corresponde a México. En conjunto, 83\% corresponde a América Latina y al Caribe.

De acuerdo con el Cuadro 2, llama la atención el flujo de inmigrantes centroamericanos. A ese respecto, en 1978 en otro documento desclasificado de la Agencia Central de Inteligencia ${ }^{7}$ se alertaba sobre el incremento de inmigrantes de esa

6 Departament of State. Memo Briefing paper on the flow and outlook of illegal migration from Mexico to the U.S. issue date: Jan 1, 1979, Declassifield: Ap. 22, 1994, reproducido en Declassifield Documents Reference System, Farmington Hills, Mich.: Gale Group, 2006, 2 pp.

7 Central Intelligence Agency, Intelligence report on the sources of illegal migration into the U.S. from Central and South America, issue date: August 1, 1978, Declassifield: Oct 20, 
Cuadro 3

Población estimada de residentes no autorizados por estado de residencia, enero 1990 y 2000 (miles)

\begin{tabular}{lrr}
\hline Estado de residencia & Población 2000 & 1990 \\
\hline Todos los estados & 7000 & 3500 \\
California & 2209 & 1476 \\
Texas & 1041 & 438 \\
Nueva York & 489 & 357 \\
Illinois & 432 & 194 \\
Florida & 337 & 239 \\
Arizona & 283 & 88 \\
Georgia & 228 & 34 \\
Nueva Jersey & 221 & 95 \\
Carolina del Norte & 206 & 26 \\
Colorado & 144 & 31 \\
Washington & 136 & 39 \\
Virginia & 103 & 48 \\
Nevada & 101 & 27 \\
Oregon & 90 & 26 \\
Massachusetts & 87 & 53 \\
Otros & 892 & 328 \\
\hline
\end{tabular}

Fuente: US Department of Homeland Security (2003).

región. En esos años, se estimaba que 90 mil personas ingresaban anualmente a Estados Unidos, situación que 20 años atrás no existía. Así, Centroamérica y Sudamérica se estaban convirtiendo en una importante región de inmigrantes ilegales. Los países que destacaban eran El Salvador, Guatemala, Colombia, Ecuador y Perú. La migración internacional de esos países hasta los años sesenta se había dirigido al sector agrícola de los países vecinos. Hoy, la frontera norte de nuestro país es la puerta de entrada de la inmigración ilegal centroamericana.

Como resultado de un proceso histórico que se manifiesta desde principios del siglo xx, casi 50\% de los inmigrantes ilegales se ubican en los estados de California y Texas. En California viven 11.9 millones de hispanos y en Texas 7.3. Cuarenta y tres por ciento de la población de Nuevo México es latina y 34\% de la población de California y Texas.

Ngai (2004) argumenta que, en la mayoría de los casos, el inmigrante ilegal ha sido estigmatizado por los estereotipos negativos raciales y etiquetados como peligrosos. Cabe señalar que en 1976 el gobierno mexicano acuñó el término de traba-

2000, reproducido en Declassifield Documents Reference System, Farmington Hills, Mich.: Gale Group, 2006, 36 pp. 
jadores indocumentados en lugar de inmigrantes ilegales, que es el utilizado en Estados Unidos. ${ }^{8}$ Hoy se emplean indistintamente los dos términos.

Como se ha mencionado, la inmigración mexicana hacia Estados Unidos se observa de manera clara desde principios del siglo xx. Uno de los principales trabajos que dan cuenta de ello es el de Manuel Gamio (1930), quien ofrece un retrato social del inmigrante mexicano de los años veinte.

En las entrevistas presentadas por Gilberto Loyo en 1951, se afirmaba que los trabajadores mexicanos sufrían discriminación en Estados Unidos (Loyo, 1969). En ese clima de desigualdad social, en esa década, César Chávez organizó The National Farm Workers Association (NFWA) para luchar contra la desigualdad laboral, movimiento que enarbola la frase: "Sí, se puede" (Bruns, 2005). En la década de los setenta, el gobierno estadounidense, por medio del Departamento de Trabajo, ${ }^{9}$ ejecutó un programa orientado a revisar los casos de los empleadores de trabajadores indocumentados con el fin de obligarlos a respetar las condiciones laborales. En 1979, se decía que como resultado de 9 mil 400 investigaciones, los empleadores debían pagarles cerca de 9 millones dólares como reembolso a cerca de 72000 trabajadores. En 2005, la empresa Wal-Mart cubrió multas y reembolsos por 11 millones de dólares aproximadamente por contratar trabajadores ilegales que realizaron labores de limpieza de las tiendas durante los turnos nocturnos.

\section{Algunos elementos de la transmigración}

Los estudios transnacionales representan en la actualidad una nueva perspectiva teórico-temática de la investigación que atiende una multiplicidad de procesos económicos, culturales, sociales y demográficos que ocurren en uno o más estadosnación. Una de las principales revistas que dan cuenta de esa diversidad de temas es Global Networks: a journal of transnacional affairs, que surgió en 2001. De manera particular, en el paradigma del transnacionalismo, se desarrolla la migración transnacional, la cual relaciona el desplazamiento de la población a los siguientes aspectos: $a$ ) las transformaciones económicas derivadas de la globalización en los

8 White House, Background information and taking points for Fords U.S. meeting with Mexican President-Elect José López Portillo, issue date: Sep 24, 1976, Desclassifield: Sep 6, 1996, reproducido en Declassifield Documents Reference System, Farmington Hills, Mich.: Gale Group, 2006, 11 pp.

9 Department of State, Briefing paper on right of undocumented Mexican workers in the U.S. Desclasificado: Apr 20 1994, reproducido en Declassifield Documents Reference System, Farmington Hills, Mich.: Gale Group, 2006, 2 pp. 
estados-nación, $b$ ) la revolución tecnológica en materia de comunicación y transportación que posibilita el desplazamiento de información, ideas y recursos financieros, y c) los cambios políticos que han implicado los procesos de descolonización, la expansión del modelo de la democracia liberal y la universalización de los derechos humanos.

La migración transnacional, como una nueva fase de la migración internacional, centra su atención en el fenómeno del mantenimiento de múltiples vínculos de los migrantes con su lugar de origen y con la reproducción de pautas de comportamiento en la sociedad receptora mediante la expansión de redes sociales y nichos económicos. A ese fenómeno se le identifica como transmigración, es decir, que el desplazamiento de la población es eminentemente social e involucra tanto los factores internos y estructurales de la sociedad receptora como los de la de origen. Dichos factores entrelazan y forman espacios transnacionales.

Desde ese punto de vista, en el caso específico de la emigración mexicana hacia Estados Unidos, la transmigración es vista como el nuevo discurso sobre el proceso de adaptación o integración, así como las razones del mantenimiento de los lazos sociales, económicos y políticos con las localidades mexicanas. La transmigración es el resultado del entrelazamiento histórico de variables internas y estructurales de cada país que están relacionadas directamente con el proceso histórico de las políticas de migración.

Como se ha mencionado, la transmigración como proceso se expresa en diversos aspectos como el migrante empresario, el flujo de remesas, la participación electoral y en los movimientos sociales transnacionales, entre otros. Cada uno de ellos constituye un espacio transnacional, cuyo análisis rebasa el objetivo de este trabajo. Por tal motivo, sólo se enuncian algunas características de tres procesos de la transmigración: las remesas, el voto en el extranjero y el retorno de migrantes.

\section{Espacio transnacional de las remesas}

Respecto del carácter histórico de la migración transnacional mexicana cabe señalar que tuvo su origen desde principios del siglo xx. Así, Waldinger (2001) reconoce que el siglo pasado fue el de la inmigración a Estados Unidos, donde la puerta trasera estuvo abierta para el ingreso de mexicanos, lo cual fue notable en el programa de braceros que se inició en 1942.

Recientemente, el flujo de migrantes mexicanos que está en aumento constante puede ser descrito como transmigración, ya que encierra diversos fenómenos de ca- 
rácter transnacional que han dado en llamarse prácticas transnacionales. Una de éstas se manifiesta en los recursos monetarios que envían los emigrantes mexicanos a sus familiares. Desde la perspectiva tradicional de la transmigración se ha enfocado el tema de las remesas hacia los motivos del envío de ellas y su uso en el lugar de origen del migrante. Sin embargo, las actuales características de la migración transnacional orientan el análisis a las implicaciones binacionales de las transferencias de remesas. Uno de los factores clave es la competencia entre los servicios bancarios de ambos países por el control del enorme flujo de remesas, ya que como advirtió el Banco Interamericano de Desarrollo, en 2006, América Latina y el Caribe recibirán más de 60 millones de dólares por concepto de remesas. Esa cifra revela la importancia económica de la migración transnacional y la formación de grandes consorcios binacionales para la transferencia de las remesas. Por ejemplo, en enero de 2007, el banco mexicano Banorte adquirió la remesadora UniTellertse, que opera en 41 de los 50 estados de Estados Unidos y cubre 97\% de la población hispana. Por tal motivo, una línea de trabajo es la estructuración de la industria de la transferencia de remesas más allá de las fronteras territoriales.

Otro elemento de la transferencia de remesas es el contexto legislativo binancional. El flujo de remesas está sujeto al marco jurídico de Estados Unidos, por ejemplo, a finales de 2006, las autoridades estadounidenses incautaron las remesas que mexicanos enviaron mediante la compañía Western Union al estado de Sonora, ya que, se argumentaba que dicho dinero se destinaba al tráfico de personas y estupefacientes. Así, el flujo de remesas está condicionado a las reglas internacionales de transferencias, que en ocasiones son desfavorables para los migrantes.

Una segunda línea de investigación toma como eje el término de transterritorialización del Estado mexicano, que ha provocado el surgimiento de una estructura de migrantes en algunas regiones de México y que reproducen el patrón de dominación paternalista mediante los programas oficiales fronterizos (Guarnizo, 1998:69-70), y que inicia la formación de migrantes empresariales. Aunque cabe señalar que el gobierno estadounidense no tiene un proyecto nacional integral sobre la comunidad de inmigrantes mexicanos, sólo cuenta con escasos programas, a pesar del volumen de emigrantes mexicanos y el monto de las remesas que ingresan a México. Cabe señalar que durante el periodo 1943-1965, la cantidad de ingresos proveniente de los braceros ascendió a 6 mil 829 millones, mientras que por concepto de turismo fue de 31 mil millones, y por la producción de oro y plata, 10 mil millones. Recientemente, las remesas ascienden a 20034.2 millones de dólares en 2005. 


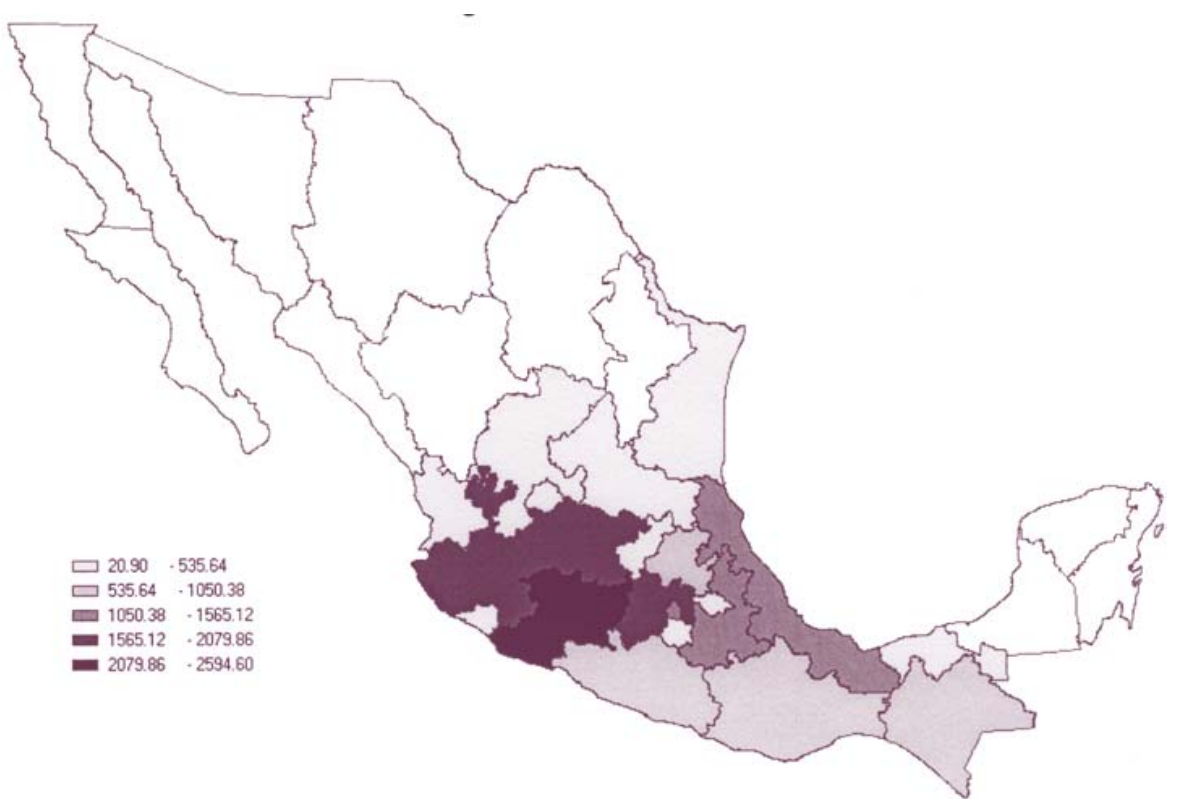

Mapa 1. Destino de las remesas de emigrantes mexicanos, 2005 (millones de dólares). Fuente: elaboración propia con datos del Banco de México (http:www.banxico.org.mx).

El monto de remesas de los emigrantes mexicanos ha ascendido de manera constante y se ha dirigido principalmente a los estados de Michoacán, Jalisco y Guanajuato, como se puede apreciar en el Mapa 1. Las remesas han sido canalizadas a la alimentación, educación y vivienda y, en mínima cantidad, a la creación de pequeños comercios.

La principal acción institucional del gobierno con los emigrantes es el programa llamado "Tres por uno", que consiste en el desarrollo de proyectos de inversión entre las organizaciones de inmigrantes mexicanos y los tres niveles de gobierno: federal, estatal y municipal. Los proyectos están destinados, principalmente, a la construcción de infraestructura: caminos, puentes, entre otros. Dicho programa es una forma de reincorporación de los emigrantes mexicanos con un esquema gubernamental.

El programa citado se desarrolla a partir de la organización de los emigrantes en el exterior, es decir, de los clubes de migrantes, que en 2003 ascendían a 623; de ellos, 126 correspondían a emigrantes de Zacatecas, 100 de Jalisco y 51 de Michoacán (Lanly, 2004:15). Los proyectos de inversión autorizados para 2003 se concentran en Zacatecas, Jalisco, Michoacán y San Luis Potosí. Sin lugar a dudas, estos proyectos son limitados e incipientes. Sin embargo, la transmigración abre la posibilidad del surgimiento del regreso de migrantes como empresarios locales. 
Cuadro 3

Votos emitidos por mexicanos en el extranjero, 2006

\begin{tabular}{lrc}
\hline País & Votos & Porcentaje \\
\hline Estados Unidos & 35746 & 87.5 \\
España & 1238 & 3.0 \\
Canadá & 861 & 2.1 \\
Francia & 509 & 1.2 \\
Reino Unido & 448 & 1.1 \\
Alemania & 393 & 1.0 \\
Italia & 212 & 0.5 \\
Suiza & 188 & 0.4 \\
Otros (incluye 72 países) & 1259 & 3.2 \\
\hline Total & 40854 & 100.0 \\
\hline
\end{tabular}

Fuente: elaborado con datos del Instituto Electoral Federal, www.ife.org.mx

\section{El voto en el extranjero}

La democracia liberal se ha convertido en la forma dominante del Estado que plantea como eje la situación en la cual la ciudadanía debe ser consultada sobre los cambios constitucionales y tiene, además, el derecho de elegir a sus gobernantes mediante la emisión del voto. Recientemente, ese derecho se extiende a la población que vive fuera de las fronteras nacionales a través del voto por carta (Hansen, 1998:58).

Aunque el voto en el extranjero tiene su antecedente en el derecho que tienen los militares y los miembros de la diplomacia desde la primera guerra mundial, es en la década de los sesenta cuando se registra mayor interés en las naciones por legislar al respecto. ${ }^{10}$

El primer ejercicio electoral para los mexicanos residentes en el extranjero se registró en 2006: por primera vez estuvieron facultados para emitir su voto para elegir al ejecutivo federal. Los mecanismos instrumentados por el Congreso de la Unión establecieron que los electores en el extranjero debían contar con la credencial emitida por el Instituto Federal Electoral (IFE), así como con un documento que acreditara el domicilio en el extranjero para el proceso de registro. Posteriormente, el elector registrado recibió información impresa y electrónica de los planteamientos electorales de los tres principales candidatos presidenciales. El IFE estimaba de manera optimista la cifra de cuatro millones de posibles electores en el extranjero,

10 De tal suerte, que en la actualidad, 40 países cuentan con legislación sobre el derecho de voto de los ciudadanos residentes en el extranjero (Carpizo, 2002), por ejemplo: Argentina, Brasil, Canadá, Colombia, Estados Unidos, Panamá, Perú, República Dominicana, España, México y otros. 
sin embargo, la forma centralizada de organizar el voto de los mexicanos en el exterior limitaron la participación de los migrantes. Así, una institución que finca su actuación en la democracia, se guió por principios centralizados, al dejar al margen, por ejemplo, a las representaciones consulares, que por su naturaleza son las oficinas que mantienen mayor comunicación con los mexicanos en el extranjero.

Los votos emitidos en el extranjero ascendieron a 40 854, es decir, $1 \%$ de los esperados por el IFE. Como se aprecia en el Cuadro 3, 97.5\% de los votos se originaron en ocho países. Cabe destacar que 87.5\% se emitieron desde Estados Unidos, $10 \%$ desde España, Canadá, Francia, Reino Unido, Alemania, Italia y Suiza. La participación fue notoriamente baja en comparación con otras experiencias registradas en diversos procesos electorales, en Argentina sufragaron 24.3\%, en Austria 25\%, en Canadá 35\% y en Colombia 64.3\% (Carpizo, 2002:82).

El hecho de la baja participación electoral de los mexicanos en el extranjero revela la presencia de obstáculos para la edificación de espacios transnacionales. Baste señalar la dificultad en la difusión en el extranjero de plataformas políticas estipuladas en la reglamentación mexicana.

\section{El retorno de emigrantes}

La migración de regreso es clave en el proceso de transmigración, ya que supera la idea del movimiento que va desde un punto de origen hacia otro, etiquetado como destino. Como se ha señalado, los estudios sobre la migración se han centrado, por una parte, en el proceso de adaptación, asimilación e integración de los inmigrantes en la sociedad receptora; y por otra parte, en las consecuencias de la emigración en las comunidades expulsoras. Sin embargo, el fenómeno de la migración de regreso ha sido escasamente abordado en los estudios migratorios, a pesar de que la tendencia aumentó en volumen e intensidad. A partir de los años sesenta se observa un interés incipiente por conocer las pautas de reincorporación de los emigrantes a la vida económica regional local, por ejemplo, se han documentado los casos de regreso de los emigrantes a Italia, Portugal y Grecia (King, 1986; Bovenkerk, 1974).

El retorno de emigrantes consiste en el proceso mediante el cual las personas regresan a su región o país de origen después de haber vivido en el extranjero en un periodo significativo. ${ }^{11}$

11 Resulta interesante reconocer que el retorno de emigrantes se observa en primer lugar en el desplazamiento de la población en sociedades con mayor igualdad de condiciones socio económicas, por ejemplo, la movilidad que se registra entre Estados Unidos, Australia y 


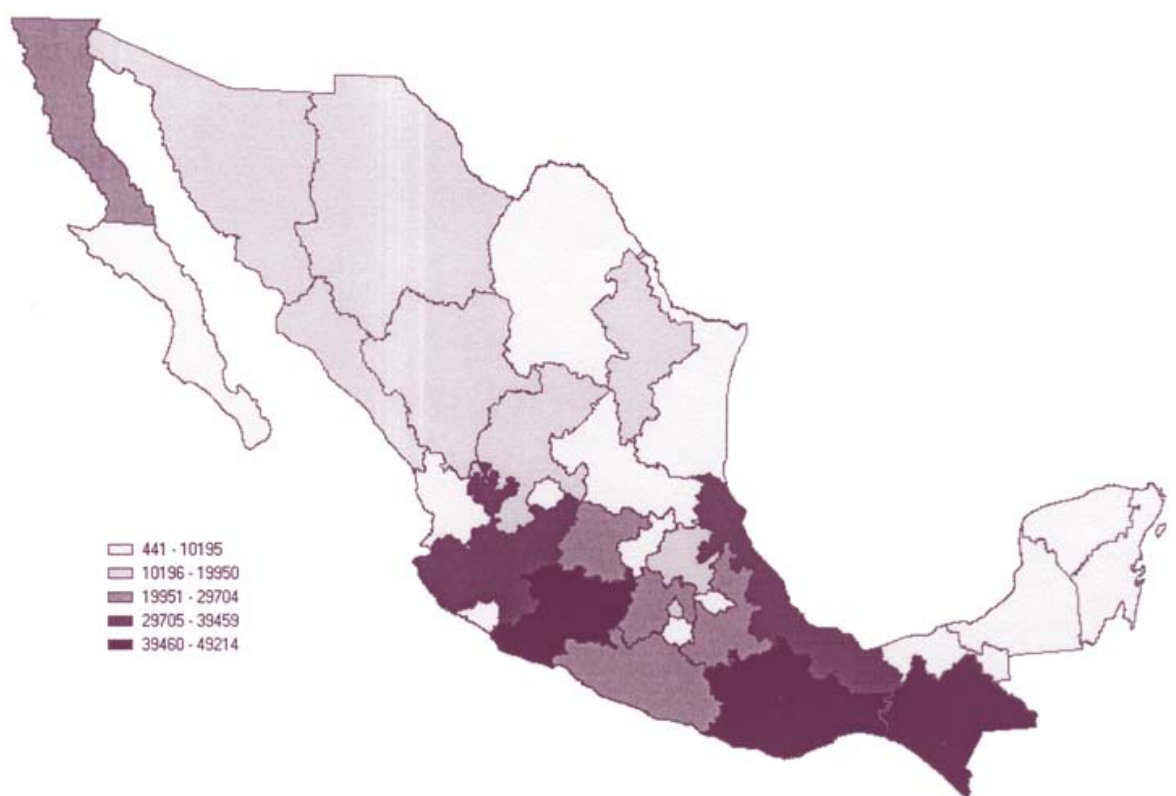

Mapa 2. Mexicanos repatriados por la Patrulla Fronteriza por Estado, 2003

Fuente: Elaboración propia con datos de Secretaría del Trabajo y Previsión Social y otros, Encuesta sobre migración en la Frontera Norte de México 2002-2003, base de datos en disco compacto

Ese tipo de migración puede generar desplazamientos de diversos tipos: a) la reemigración, cuando los emigrantes se desplazan nuevamente a la misma sociedad receptora; $b$ ) la emigración de segundo momento se registra cuando después de haber regresado al lugar de origen se desplazan a un tercer lugar. c) La migración circular, cuando se repiten el desplazamiento en el punto origen y de recepción, como el caso de mexicanos que cada año regresan a su lugar de origen por motivos religiosos y familiares. Ésa puede adquirir la modalidad de migración temporal, siempre y cuando los movimientos sean regulares; en ciertas ocasiones obedece a los ciclos agrícolas y a la demanda de trabajadores. Por ejemplo, los trabajadores temporales mexicanos en Canadá, que inició con 203 trabajadores en 1974 y alcanzó la cifra de 10681 en 2002 (Basok, 2002; Verea, 2003:171-177). Finalmente, la

Canadá. En segundo lugar, la movilización de personas de los países subdesarrollados a los desarrollados se observa principalmente en los que fueron colonizados, por ejemplo, franceses de Argelia, belgas del Congo, británicos de Kenia y portugueses de Angola. En tercer lugar, es quizás el más importante porque se refiere al retorno de trabajadores y sus familias de los países desarrollados a los de origen, en este caso abastecedores de mano de obra, por ejemplo: indios del Reino Unido, los turcos de Alemania y mexicanos de Estados Unidos. 
migración de regreso en la modalidad de repatriación, que se observa cuando el retorno del emigrante no responde a su iniciativa, sino a que son forzados por eventos políticos, naturales o por autoridades.

En el caso de los mexicanos repatriados por las autoridades estadounidenses, en particular por la Patrulla Fronteriza, ascendió a 481 mil personas en 2003, de las cuales $83 \%$ son hombres (STPS, 2004:69). La mayoría de los repatriados son originarios de Chiapas, Oaxaca y Michoacán, como se muestra en el Mapa 2.

El regreso de emigrantes representa un flujo constante en México por la repatriación y por el retorno temporal. Cada año regresan millones de emigrantes de manera transitoria. Sin embargo, los gobiernos estatales muestran escaso interés en su retención. El movimiento constante de dichos migrantes forma parte de la transmigración, el cual le da sentido a la frase "emigrar para regresar".

\section{Comentario final}

La política migratoria de Estados Unidos ha diferenciado con claridad meridiana el flujo de mexicanos, en comparación con los europeos. Esa diferencia es patente en la histórica presencia de la inmigración indocumentada desde principios del siglo xx. Al parecer, las teorías de la migración que abordan el proceso de movilidad internacional en América de Norte han tenido dos claros momentos de reflexión, a saber: los procesos de asimilación de la población de origen europeo hasta la mitad del siglo pasado, y los procesos de transnacionalismo de la población no europea, como la asiática y la de latinoamerica en el último cuarto del siglo xx. Por un lado, el melting pot europeo, y por el otro, el enclave étnico de las comunidades latinoamericanas y asiáticas son dos formas de comprender el proceso de migración, que dan cuenta de la desigualdad social en los tipos de migración.

El proceso de incorporación del inmigrante ha sido observado desde tres perspectivas metodológicas. En primer lugar, la incorporación se expresa en un conjunto de relaciones simbólicas unilaterales, sin considerar la estructura social, en la cual se presentan inequidades sociales, políticas, económicas y procesos de dominación. En segundo lugar, la incorporación se manifiesta en un grupo de relaciones de intercambio igualitarias, en donde se dan relaciones de incorporación que revelan intercambios culturales y su acomodo sin ser reducido. Finalmente, el tercer punto de vista que califica las relaciones de incorporación como un fenómeno de contaminación y deterioro. Desde estas tres visiones, el transnacionalismo se erige como un avance en los estudios sobre el transmigrante al atender la construcción de espa- 
cios sociales para comprender la incorporación del inmigrante en la sociedad receptora y en la creación de lazos transnacionales con la sociedad emisora. Sin embargo, aún queda un largo camino por recorrer para comprender la interacción de las comunidades de inmigrantes legales e ilegales con la estructura social, económica y política de la sociedad receptora.

\section{Bibliografía}

Appadurai, Arjun, La modernidad desbordada: dimensiones culturales de la globalización. Buenos Aires, FCE, 2001.

Basch, Linda; Nina Glick Schiller y Cristina, Nations Unbound: Transnational Projects, Postcolonial Predicaments, and Deterritorialized Nation-States, 2a. edición, Amsterdam, Gordon and Breach Science Publishers, 1995.

Basok, Tanya, Tortillas and Tomatoes: Transmigrant Mexican Harvesters in Canada. Montreal y Kingston, McGill-Queen's University Press, 2002.

Bonacich, Edna, "A theory of ethnic antagonism: the split labormarket", en American Sociological Review núm. 37, octubre, pp. 547-559.

Bovenkerk, Frank, The sociology of return migration: a bibliographic essay, Martinus Nijhoff: The Hague, 1974.

Bruns, Roger, César Chávez: a biography, West Port, Connecticut, Greenwood Press, 2005.

Carpizo, Jorge, "El voto de los mexicanos en el extranjero: contexto, peligros y propuestas", en El voto de los mexicanos en el extranjero, J. Carpizo y D. Valadés (editores), México, UNAM- Editorial Porrúa, 2002.

Fairchild, Henry P., The Melting-Pot Mistake. Boston: Little, Brown, and Company, 1926.

Gamio, Manuel, Mexican Immigration to the United States: a study of human migration and adjustment, Chicago, The University of Chicago Press, 1930. - Mexican Immigration in the United States: a study of human migration and adjustment, Chicago, The University of Chicago Press, 1969.

Ganzevoort, Herman, The Last Illusion: Letters from Dutch Immigrants in the "Land of Opportunity”, 1924-1930, Legacies Shared, Calgary, University of Calgary Press, 1999.
Gordon, Milton M., Social Class in American Sociology, Durham, North Carolina, Duke University Press, 1958.

, Assimilation in American Life: The Role of Race, Religion, and National Origins, Nueva York, Oxford University Press, 1964.

Grewal, Inderpal, Transnational America, Feminisms, Diasporas, Neoliberalisms, Durham y Londres, Duke University Press, 2005.

Guarnizo, Luis E., "The Rise of Transnational Social Formations: Mexican and Dominican State Responses to Transnational Migration", en Political Power and Social Theory, D.E. Davis (editor), Stanford y Londres, Jai Press, 1998.

Hansen, Mogens H., Polis and City-State: an Ancient Concept and its Modern Equivalent, 5 vols., Acts of the Copenhagen Polis Centre, Copenhagen: The Royal Danish Academy of Sciences and Letters, 1998.

Herrera Carassou, Roberto, La perspectiva teórica en el estudio de las migraciones, México, Siglo XXI, 2006.

Kallen, Horace M., Culture and Democracy in the United States: studies in the group of psychology of the American peoples, reimpresión 1970, Nueva York, Arno Press y The New York Times, 1924.

, American Idea: an essay in Social Philosophy, Inglaterra, India y Paquistán, University of Pennsylvania Press, 1956.

King, Rusell (editor), Return Migration and Regional Economic Problems, Londres, Croom Helm, 1986.

Lanly, Guillaume y M. Basilia Valenzuela V. (editores), Clubs de migrantes oriundos mexicanos en los Estados Unidos: la política transnacional de la nueva sociedad civil migrante, Guadalajara, Universidad de Guadalajara, 2004. 
Loyo, Gilberto, "Notas preliminares sobre la inmigración de mexicanos a los Estados Unidos de 1900 a 1967", en El inmigrante mexicano, M. Gamio (editor), México, Instituto de Investigaciones Sociales, UNAM, 1969.

Mahler, Sarah J., "Theoretical and Empirical Contributions Toward a Research Agenda for Transnationalism", en Transnationalism from below, M.P.S. y L.E. Guarnizo (editores), New Brunswick y Londres, Transaction Publishers, 1998.

Martin, Philip L., "The United States: The Continuing Immigration Debate, en Controlling Immigration: a global perspective, W.A. Cornelius, Takeyuki Tsuda, Philip L. Martin y James F. Hollifield (editores), California, Stanford University Press, 2004.

Nahshon, Edna (editor), From the Ghetto to The Melting Pot: Israel Zangwill's Jewish Plays, Detroit, Wayne State University Press, 2006.

Ngai, Mae M., "Impossible Subjects: illegal aliens and the making of modern America, en Politics and Society in Twentieth-Century America", en G.G. William Chafe, Linda Gordon y Julian Zelizer (editores), Princeton y Oxford, Princeton University Press, 2004.

Park, RobertE., "The Inmigrant Press and its Control", enA.T. Burns (editor), Americanization Studies, Westport, Connecticut, Greenwood Press, 1922.

Park, Robert E. y Ernest W. Burgess , "Introduction to the Science of Sociology including the original index to basic sociological concepts", en M. Janowitz (editor), tercera edición, The Heritage of Sociology, Chicago, Chicago University Press, 1921.
Satzewich, Vic y Lloyd Wong (editores), Transnational Identities and Practices in Canada, Vancouver y Toronto, UBC Press, 2006.

Steinfield, Melvin, Cracks in the Melting Pot: racism and discrimination in American history, Beverly Hill, Glencoe Press, 1970.

Secretaría del Trabajo y Previsión Social, Encuesta sobre migración en la Frontera Norte de México 2002-2003, México, Dirección General de Investigación y Estadísticas del Trabajo (STPS), 2004.

Theodorson, G.A., Estudios de ecología humana, 2 vols, Barcelona, Editorial Labor, 1974.

Tonnies, Ferdinand, Community \& Society: Gemeinschaft und Gesellschaft, Nueva York, Harper \& Row, 1963.

Verea, Mónica, Migración temporal en América del Norte: propuestas y respuestas, México, CISAN-UNAM, 2003.

Waldinger, Roger, "The Immigrant Niche in Global City-Regions: Concept, Patterns, Controversy", en Global City-Regions, A.J. Scott (editor), Oxford y Nueva York, Oxford University Press, 2001.

Weintraub, Sidney y Stanley R. Ross, The Illegal Alien from Mexico: Policy choices for an intractable issue, Austin, University of Texas Press, 1980.

Zangwill, Israel, "The Melting Pot: Drama in Four Acts", en From the Ghetto to the Melting Pot: Israel Zangwill's Jewish Plays, E. Nahshon (editor), Detroit, Wayne State University Press, 1908. 